\title{
A REALIDADE AUMENTADA COMO RECURSO NA APRENDIZAGEM DE LOGÍSTICA E TRANSPORTES: SIMULAÇÃO DE MOVIMENTAÇÃO DE MATERIAIS
}

\author{
AUGMENTED REALITY AS A RESOURCE IN LEARNING LOGISTICS AND TRANSPORT:
} SIMULATION OF MATERIAL MOVEMENT

Juliana Ferreira de Vales ${ }^{1}$, Allex Martins Campos², Gabriel Bulgarelli Nunes ${ }^{3}$, Nathalia Nobrega Chagas ${ }^{4}$, Orlando Fontes Lima Junior ${ }^{5}$

DOI: 10.37702/REE2236-0158.v40p149-159.2021

\section{RESUMO}

A realidade aumentada é uma ferramenta que insere elementos reais e virtuais, através da possibilidade de se sobrepor o ambiente real com elementos computacionais, sendo capaz de ampliar os sentidos e habilidades do ser humano. Esse recurso transformador em diversas áreas, como treinamento e educação, permite maior interatividade e, assim, a criação de ambientes colaborativos de aprendizagem. Esta pesquisa procurou contemplar as possibilidades de aplicação e os benefícios da realidade aumentada na educação, mas principalmente nas disciplinas de simulação de movimentação de materiais. Foi desenvolvido um modelo interativo e personalizável para auxiliar o aluno que poderá ser utilizado em aulas de movimentação, composto por um armazém virtual, uma maquete e uma empilhadeira eletrônica. O modelo foi executado e se mostrou muito útil no auxílio quanto a noções espaciais, manuseio de cargas, podendo ser, futuramente, aprimorado e empregado em cursos de capacitação ou em aulas práticas.

Palavras-chave: realidade aumentada; educação; logística.

\begin{abstract}
Augmented reality is a tool that inserts real and virtual elements, through the possibility of overlapping the real environment with computational elements, being able to extend the senses and skills of the human being. This transformative resource in many areas, such as training and education, allows for greater interactivity and, thus, the creation of collaborative learning environments. This research, in its first phase, sought to contemplate the possibilities of application, and its benefits, of augmented reality in education, but mainly in simulation of material movement. Then, an interactive and customizable model was developed to help the student, which could be used in moving lessons, consisting of a virtual warehouse, a model and an electronic forklift. The model was executed, it proved to be very useful in terms of spatial notions, handling of loads, and could be improved and used in training courses or practical classes in the future.
\end{abstract}

Keywords: augmented reality; education; logistics.

\footnotetext{
${ }^{1}$ Pesquisadora e Mestranda em Engenharia Civil na Faculdade de Engenharia Civil, Arquitetura e Urbanismo - FEC -UNICAMP, Laboratório de Aprendizagem em Logística e Transportes - LALT; julianadevalles@gmail.com

${ }^{2}$ Pesquisador e Graduando em Física na UNICAMP - Laboratório de Aprendizagem em Logística e Transportes - LALT

allexrm@gmail.com

${ }^{3}$ Pesquisador e Graduando em Engenharia Civil na Faculdade de Engenharia Civil, Arquitetura e Urbanismo - FEC -

UNICAMP, Laboratório de Aprendizagem em Logística e Transportes - LALT; gbnunes@ymail.com

${ }^{4}$ Pesquisadora e Graduanda em Engenharia Civil na Faculdade de Engenharia Civil, Arquitetura e Urbanismo - FEC -UNICAMP, Laboratório de Aprendizagem em Logística e Transportes - LALT Cidade Universitária; nathnchagas@gmail.com

${ }^{5}$ Professor Titular do Departamento de Geotecnia e Transportes da FEC-UNICAMP, Faculdade de Engenharia Civil, Arquitetura e Urbanismo - FEC, Laboratório de Aprendizagem em Logística e Transportes - LALT;

oflimaj@fec.unicamp.br
} 


\section{INTRODUÇÃO}

Mediar os processos de ensino e aprendizagem atualmente não é uma tarefa fácil. Principalmente porque vivenciamos um impulso das Tecnologias de Informação e Comunicação (TIC), e muitos equipamentos e aplicativos estão sendo utilizados no dia a dia, e nas salas de aulas não poderia ser diferente. $\mathrm{O}$ uso das tecnologias tem possibilitado um aprendizado mais significativo, modificando a forma de como o conhecimento é compartilhado entre professores e alunos na sala de aula (PRENSKY, 2012).

Apesar da evolução tecnológica, o modelo de ensino o qual vivenciamos não é muito diferente dos moldes do passado, ou seja, não utiliza, em sua grande maioria, as vantagens que a tecnologia traz para dentro da sala de aula. De acordo com Santos e Rezende (2014, n.p.) "No meio educacional é preciso acompanhar essas mudanças e estar preparado para tal, pois ao rejeitar esse cenário, o impacto será em aulas que desmotivam os alunos e formam cidadãos alheios à realidade imposta".

De acordo com Pedrosa e ZappalaGuimarães (2019), as novas práticas educacionais não decorrem simplesmente da introdução de tecnologias - não se pode associar o simples uso dessas tecnologias à inovação e à melhoria da qualidade do processo de ensino e aprendizagem. Com isso, para a inclusão de conteúdo, sua utilização deve ser estudada e o seu potencial avaliado para que haja uma contribuição didática.

Ainda de acordo com Prensky (2012), os alunos do século XXI são muito diferentes daqueles alunos para os quais o modelo escolar predominante foi criado. Assim, o uso das novas TICs pode ser um aliado importante para motivar os alunos nos processos educativos, como a construção da aprendizagem. Entre estas novas TICs, a realidade aumentada (RA) vem despontando como uma das mais promissoras, apresentando um grande potencial de utilização no âmbito educacional (HAMILTON, 2011).

Diversas áreas têm se beneficiado dos avanços tecnológicos apresentados pela RA, e a educação é um bom exemplo. Azuma et al.
(2001) cita a educação como uma das principais áreas de aplicação da RA, pois ela pode se aproveitar da capacidade de apresentação de informações permitidas pela tecnologia para adicionar camadas de informação sobre objetos e locais, facilitando o processo de aprendizado.

A RA permite o usuário ver o mundo real, com os objetos virtuais sobrepostos ou compostos com o mundo real, utilizando dois ambientes simultaneamente (AZUMA, 1997).

De um modo geral, remete a qualquer tecnologia que harmonize informações reais e virtuais de maneira significativa (KLOPFER, 2008). Suas aplicações podem ser desenvolvidas de diversas formas, fazendo com que esta seja uma ferramenta flexível e, devido a isso, muito útil na área educacional.

Os conceitos de realidade aumentada e virtual começaram a ser mais propriamente estudados na década de 1990, quando Milgram et al. (1994) propuseram a ideia de um "contínuo de realidade-virtualidade", em que a realidade aumentada seria uma forma de realidade virtual, mas na qual o indivíduo portasse um equipamento que ainda permitisse uma visão clara do mundo real.

Nos anos 2000, autores passaram a estudar a realidade aumentada aplicada à educação. Segundo Mase, Kadobayashi e Nakatsu (1996), Kirner e Zorzal (2005) e Liarokapis e Anderson (2010), por ser um recurso adaptável a diferentes situações, a realidade aumentada é um poderoso instrumento em diversos níveis da área da educação. Assim, a RA proporciona, através da exploração entre real e virtual, maior dinamização e integração entre grupos de pessoas, sendo muito utilizada no desenvolvimento de ambientes colaborativos.

No campo da logística e transportes, a realidade aumentada é largamente utilizada na otimização de processos como armazenamento, empacotamento, manuseio e transporte de mercadorias. Em grandes empresas do ramo, por exemplo, essa ferramenta otimiza processos como o de retirada eletronicamente assistida de materiais, fundamentado na utilização de óculos de realidade aumentada pelos funcionários na tarefa de selecionar mercadorias com base no pedido do cliente: os óculos indicam a melhor rota para se chegar até 
o corredor onde está localizada a mercadoria e, também, a posição desta na prateleira. Segundo Kückelhaus (2015), a adoção dessa medida foi responsável, nos armazéns da DHL, por um aumento de em média $25 \%$ na produtividade de cada funcionário.

Outra função importante da realidade aumentada seria o treinamento e capacitação de profissionais da área, como treinamento de motoristas com relação a questões de segurança, pois outra dimensão importante para a aprendizagem é o acoplamento entre cognição e experiência física, de acordo com O'Malley e Stanton Fraser (2004).

A empresa DOT Digital Group (2019) relatou um crescimento estimativo de $95 \%$ entre os anos de 2016 a 2024 no mercado de Smart glasses (óculos inteligentes); também foi relatado que até 2025 serão investidos US\$ 22,5 bilhões na realidade virtual voltada para a educação; e, até o final de 2020, o investimento com RA seria de $271 \%$.

Este trabalho teve o objetivo de pesquisar e exemplificar o uso da realidade aumentada como recurso de ensino e aprendizagem de conteúdos relacionados à logística e transportes. Para tanto, foi desenvolvido um modelo de simulação para movimentação, que poderá ser utilizado em aulas práticas do curso de logística, que auxilia o aluno, em maiores noções de espaço e de maior familiaridade com os controles de deslocamento e de manuseio de mercadorias.

\section{REALIDADE AUMENTADA}

Estudiosos do uso das tecnologias em educação (MATTAR, 2010; KENSKI, 2012; CARVALHO; IVANOFF, 2010) relatam que os recursos digitais podem facilitar de várias maneiras os processos de ensino e aprendizagem. Em uma aula que seria basicamente expositiva, esses recursos são capazes de ajudar o professor a construir conceitos e compartilhar conhecimentos, criando um ambiente mais dinâmico e interativo para todos os envolvidos.

As possibilidades do uso da Realidade Aumentada (RA) têm como limite somente a criatividade. A RA pode ser usada, inclusive, no entretenimento, para criação de jogos ainda mais interativos, como foi o caso do sucesso do Pokémon Go. Para as empresas, essa tecnologia tem sido muito usada por varejistas no setor de móveis e decoração, permitindo que clientes vejam como o produto vai ficar em sua casa antes mesmo de irem até a loja (DOT DIGITAL GROUP, 2017).

De acordo com a DOT Digital Group (2017), a empresa Walmart é a maior varejista do mundo e utiliza RA no treinamento dos funcionários. Óculos de Realidade Virtual são utilizados em conjunto com fones de ouvido, simulando situações no trabalho - como atendimento de clientes e até a realização da limpeza de um ambiente. $\mathrm{O}$ funcionário é acompanhado por um instrutor no treinamento, que avalia o desempenho em uma tela de vídeo durante a aula.

A realidade aumentada traz um grande impacto na interação de pessoas com equipamentos virtuais, pois é uma nova maneira de estar em contato de forma simples, rápida e barata com qualquer tipo de informação virtual relacionada a alguma máquina por exemplo (TORI; KINER, 2004).

\section{Realidade aumentada na educação}

A realidade aumentada na educação já não é uma novidade, visto que algumas instituições de ensino já utilizam esse tipo de tecnologia. Grande parte das aplicações de RA ocorre em áreas como entretenimento e marketing, mas cresce significativamente na educação (HAMILTON, 2011).

As tecnologias podem ser um meio de promover formas mais lúdicas de ensino, tornando o processo muito mais dinâmico e atraente aos alunos, pois estes se dispersam facilmente e esses meios tecnológicos são inseridos na sociedade e geram impactos diretos na educação. Em outras palavras, tratase de conectar os meios tecnológicos à realidade no âmbito educacional, evidenciando que a qualidade do ensino pode tomar rumos mais atuais e muito mais atrativos (CASTRO et al. 2014).

De acordo com Silveira e Araújo Jr (2006), as instituições acadêmicas são desafiadas por 
essas novas tecnologias e estão adotando estratégias mais apropriadas para atender a uma demanda educacional inovadora.

Por isso a utilização de RA para fins educativos tem sido avaliada de forma intensiva nos últimos anos, e os resultados dessas avaliações mostram ganhos, em termos de aprendizagem, maiores do que outras formas de interação, utilizando-se a educação mediada por computador (CARDOSO; LAMOUNIER JR., 2009). De acordo com Mendonça e Mustaro (2011), a realidade aumentada em educação pode constituir um elemento motivador e despertar a atenção do discente.

Diversos autores com o Chang, Morreale e Medicherla (2010) sugerem que para melhorar a motivação e a aprendizagem dos alunos, deve-se aprimorar as práticas na utilização da realidade aumentada.

\section{DESENVOLVIMENTO DO MODELO DE RA}

Para exemplificar uma das possibilidades do uso da realidade aumentada na educação, foi criado um modelo para auxiliar os alunos na disciplina de Logística, Simulação de Movimentação de Materiais. Ademais, o modelo também poderá servir para futura utilização dos alunos do LALT (Laboratório de Aprendizagem em Logística e Transportes). De acordo com Campos, Nunes e Chagad (2018), o modelo é composto por três partes: um software de armazém, que constitui um elemento virtual e uma maquete e uma empilhadeira eletrônica, que são elementos reais. Tal combinação de elementos reais e virtuais ilustra o conceito de realidade aumentada, apresentado no início.

A empilhadeira é montada utilizando o kit de montagem robótica Lego Mindstorms EV3 e emparelhada via Bluetooth a um computador. Conecta-se também ao computador uma placa Arduino e é ligado a esta um controle Nunchuk de Nintendo Wii.

\section{Figura 1 - Esquema de funcionamento da empilhadeira}

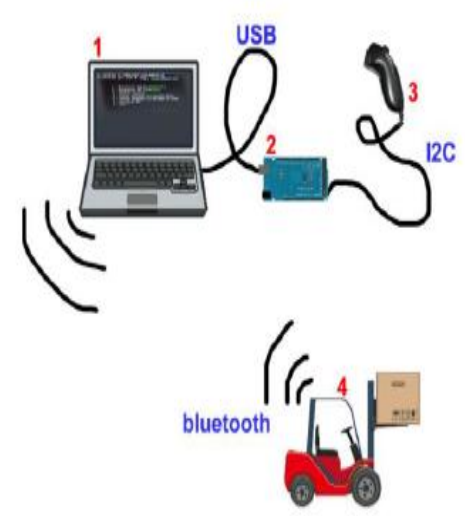

Fonte: acervo dos autores.

Na Figura 2, os elementos são os seguintes: Notebook com os drivers para Arduino e softwares necessários instalados; Placa Arduino; Controle Nunchuk de Nintendo Wii; Empilhadeira.

Alguns fundamentos do funcionamento da empilhadeira são os seguintes:

a) O Wii Nunchuck se comunica com o Arduino através do protocolo I2C (Inter-Integrated Circuit). O Arduino converte os dados recebidos pelo I2C e os reenvia para o computador através da porta Serial (USB). Deve estar rodando um programa que faz a conversão dos sinais $\mathrm{I} 2 \mathrm{C}$ em Serial;

b) O computador deve estar executando um programa que recebe os dados do Nunchuck via Serial e converte em comandos texto que são enviados via Bluetooth para a empilhadeira.

c) A empilhadeira deve estar executando um programa que recebe os comandos texto, interpreta e executa a ação solicitada (andar, girar ou mover verticalmente o garfo). 
Figura 2 - Lego Mindstorms EV3
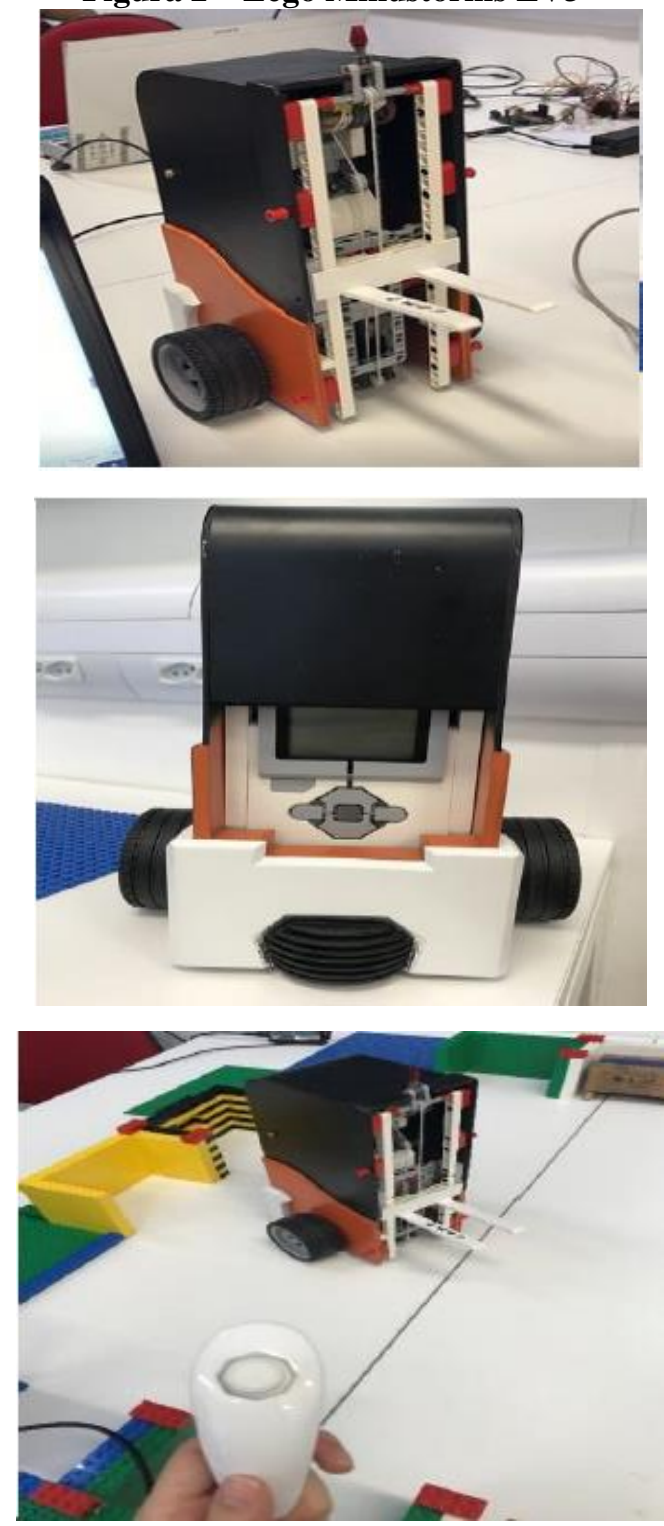

Fonte: acervo dos autores.

No caso da maquete, ela pode ser montada com diversos materiais e em diversas formas. É importante que seja colocada sobre uma superfície lisa e plana. Para essa aplicação, foi montada no laboratório uma maquete utilizando peças de Lego, que foi posicionada sobre uma mesa. A maquete (Figura 3), com espaço interno de $67 \times 82 \mathrm{~cm}$, representa um galpão de formato retangular e sem prateleiras no meio, apenas nas laterais.
Figura 3 - Maquete montada em Lego e empilhadeira

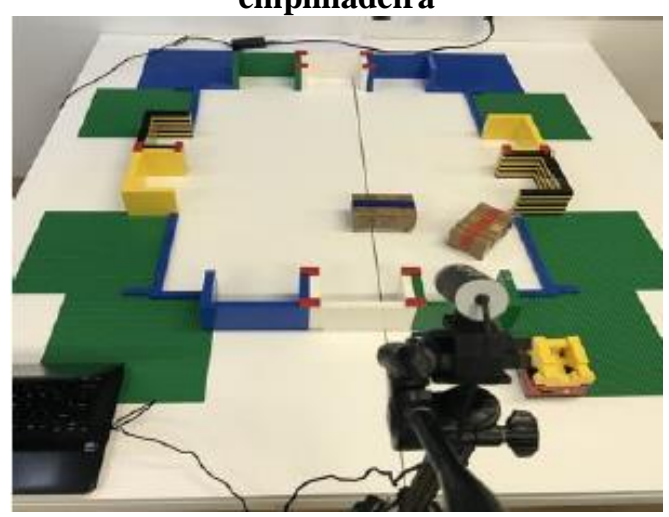

Fonte: acervo dos autores.

O armazém virtual, desenvolvido no próprio laboratório, na notação de programação JSON (JavaScript Object Notation), é acessado através de um computador, pelo endereço http://lalt.fec.unicamp.br/ar/warehouse/. É possível utilizar essa ferramenta com e sem uso de uma câmera. Utilizando a câmera, as linhas do armazém são exibidas sobre a superfície filmada por esta.

Ao acessar a interface, é possível criar um projeto ou alterar um projeto existente. No entanto, para que qualquer alteração seja salva, é necessário inserir a chave do proprietário, enviada para o e-mail do usuário mediante um cadastro. Ao abrir um projeto pela primeira vez, é exibida a tela conforme a Figura 4:

Figura 4 - Tela inicial de projeto

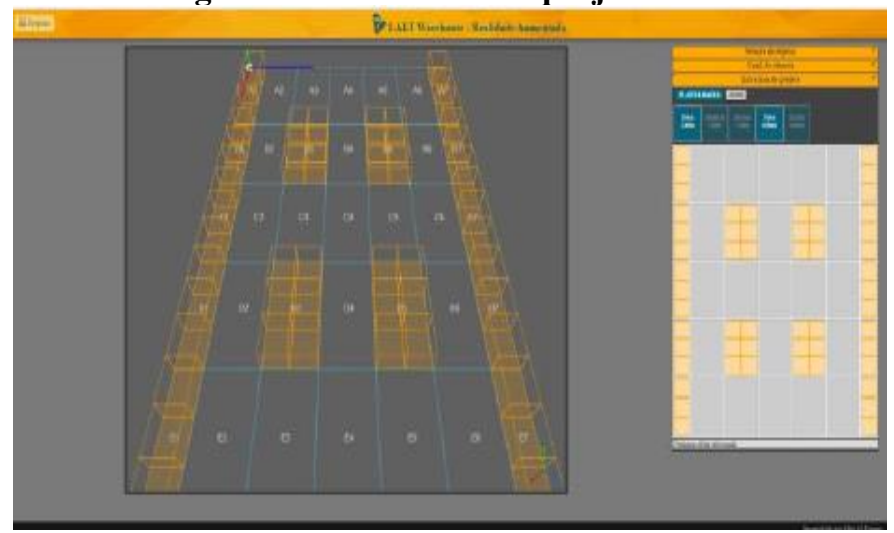

Fonte: acervo dos autores. 
Figura 5 - Configurações do armazém

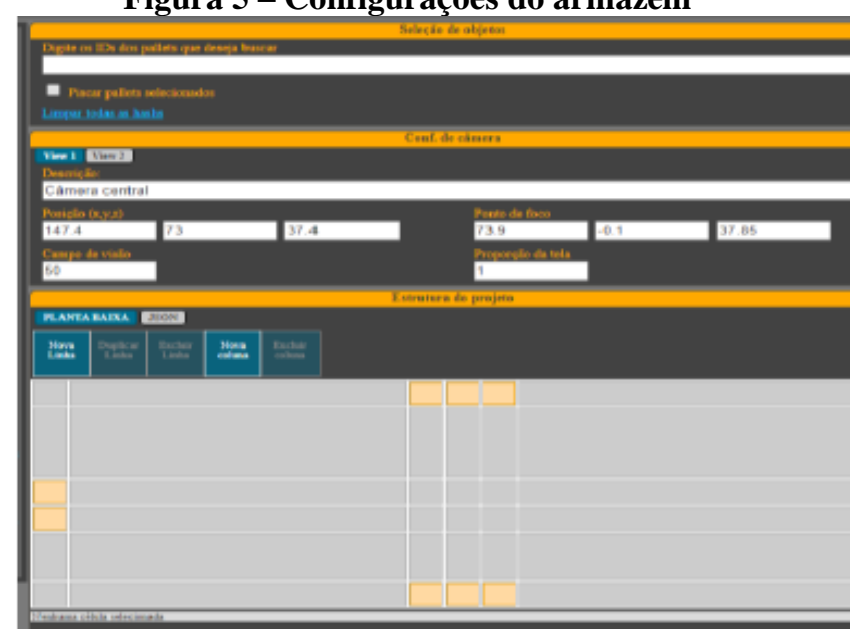

Fonte: acervo dos autores.

É possível alterar a configuração do armazém, exibido na parte esquerda da Figura 5, de duas formas:

a) através da planta baixa (localizada na parte direita da Figura 5) - é possível criar, duplicar ou excluir linhas e colunas, assim como definir uma célula como rua ou prateleira e, no caso da prateleira, definir se a armazenagem será no lado direito, esquerdo ou em ambos;

b) também é possível alterar configurações do armazém com relação à câmera (como posição, campo de visão, ponto de foco e proporção da tela).

Outro recurso importante é o de destaque de uma determinada célula. É possível selecionar um determinado objeto utilizando um código de três algarismos (chamado de ID), em que o primeiro se refere à linha do objeto, o segundo à coluna e o terceiro à posição do objeto na prateleira. Para selecionar uma célula e destacá-la com determinada cor, deve-se digitar o ID desta na seção 'Seleção de objetos', seguido por dois pontos (:) e o código hexadecimal da cor desejada, conforme a Figura 6.
Figura 6 - Função destaque de objetos

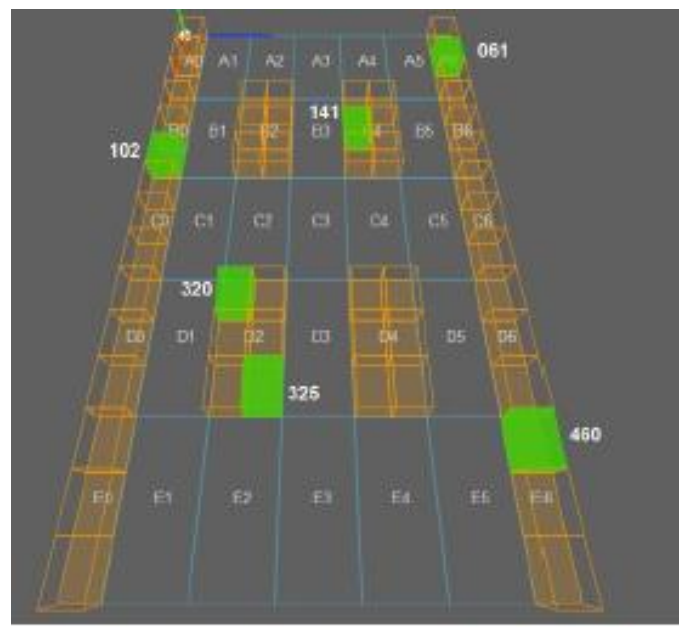

Fonte: acervo dos autores.

\section{Implantação do modelo de RA}

Procurando exemplificar o funcionamento do sistema proposto, foram verificadas duas possibilidades de uso educativo integrando a empilhadeira, a maquete e o armazém virtual. Ambas utilizaram o recurso de destaque de uma determinada célula do armazém. Para a captura de fotos e vídeos, foi empregado o software CamStudio - Screen Recorder.

Em ambos os casos, a montagem foi feita da seguinte forma: a maquete foi montada e posicionada sobre uma mesa plana e em seu interior foi colocada a empilhadeira, já ligada e configurada. Em um tripé, posicionou-se uma câmera USB, que foi conectada a um notebook (Figura 7). Neste mesmo notebook foi aberto o armazém e, então, ajustou-se a câmera de forma que o armazém sobrepusesse a maquete de maneira satisfatória, conforme a Figura 8.

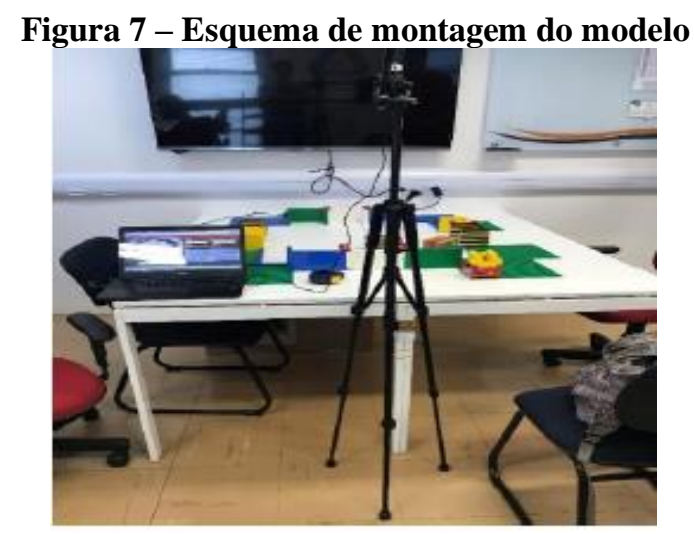

Fonte: acervo dos autores. 
Figura 8 - Captura de tela mostrando o software

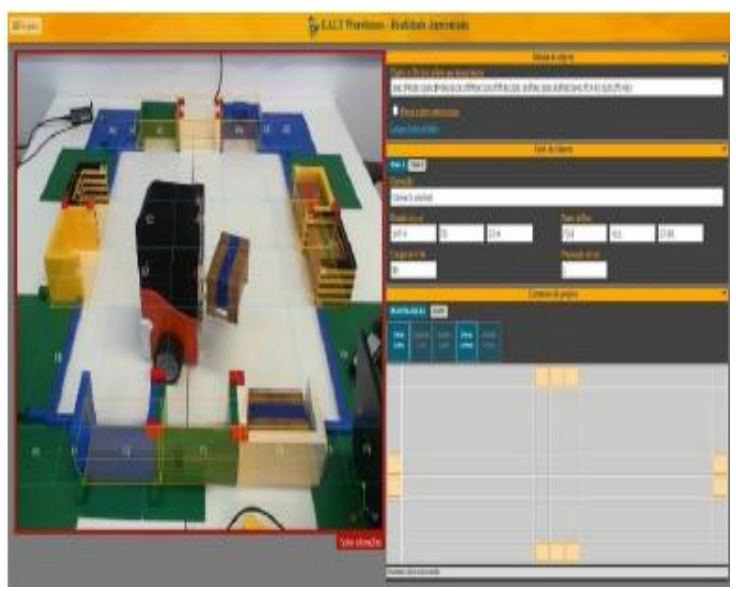

Fonte: acervo dos autores.

Em um primeiro momento foram destacados vários pares de prateleiras, cada par com uma cor diferente, com o propósito de utilizar a empilhadeira para coletar a carga de uma prateleira e levar até a outra de mesma cor conforme a Figura 9. A cada vez que uma carga era transportada, a cor do par de prateleiras era apagada, facilitando na organização das tarefas pelo aluno.

Esta atividade procurou familiarizar o discente com os controles de deslocamento (mas sem precisar seguir uma rota específica), com o levantamento de garfo da empilhadeira, ensinando-o a perceber qual deve ser a profundidade do garfo embaixo da caixa antes de levantá-la (se o garfo for encaixado muito no fundo ou muito no começo do pallet, este pode cair ao ser levantado) e, também, com a manobra da empilhadeira.

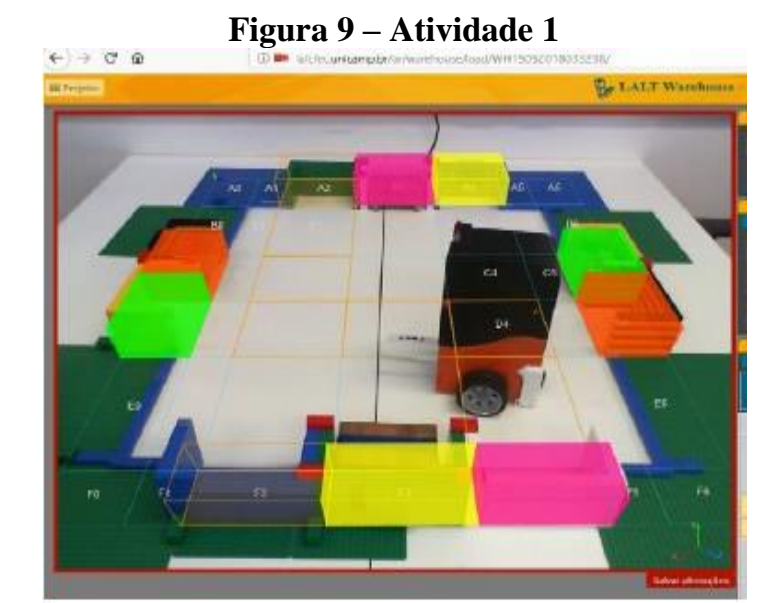

Fonte: acervo dos autores.
Em seguida, foi realizado outro teste: foi definida a melhor rota de uma prateleira a outra, e a empilhadeira foi deslocada por tal caminho. Esse teste serviu para que o discente se acostumasse com a precisão da empilhadeira, manuseando os controles de forma que esta não saísse da rota laranja, conforme a Figura 10. É importante ressaltar que o software não é capaz de calcular a rota mais curta, apenas é possível escolher um caminho e destacar as células deste.

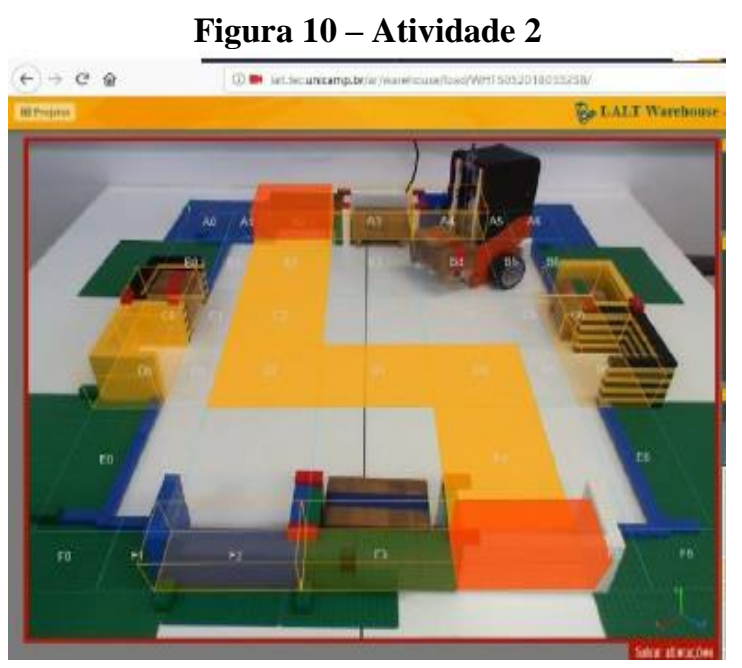

Fonte: acervo dos autores.

\section{RESULTADOS E DISCUSSÕES}

Por meio dos testes e procedimentos realizados, pode-se verificar que o sistema possui uma interface simples e fácil de ser utilizada por indivíduos sem experiência, além de que é possível ter uma boa noção dos comandos apenas lendo o manual.

No primeiro teste realizado, em que o aluno deve coletar a carga de uma prateleira e transportar até outra, sem seguir uma rota determinada, foi observado que o sistema é muito útil na organização, pois é possível destacar em cores diferentes onde está localizada cada carga e, também, onde deve-se colocá-la, eliminando a necessidade do uso de listas de papel nesse processo.

No segundo teste, em que o aluno deve deslocar a empilhadeira ao longo de uma rota especificada, houve algumas dificuldades: como o armazém é sobreposto à maquete, o trajeto colorido inibiu um pouco a visibilidade 
da empilhadeira através do monitor, fazendo com que fosse necessário, algumas vezes, olhar diretamente na maquete. Além disso, a falta de precisão da empilhadeira fez com que fossem necessárias manobras para se manter na rota.

De um modo geral, o modelo desenvolvido possui pontos positivos e, também, pontos a serem aprimorados. Alguns de seus benefícios foi a simulação para movimentação de materiais, que auxilia no ganho de noção de espaço, assim como nos controles de deslocamento e levantamento de garfo, reduzindo acidentes durante um posterior caso em que haja um treinamento com uma empilhadeira real. Ainda, deve ser notado que os componentes do sistema (armazém virtual, maquete e empilhadeira) também podem ser utilizados separadamente. Pode ser desenvolvido um sistema, por exemplo, para que o armazém virtual seja sobreposto a um galpão real e seja empregado no dia a dia de empresas de logística e transportes, para uso com empilhadeiras reais, auxiliando na visibilidade dos operadores.

Como quesitos a serem aprimorados, alguns dos principais são a falta de precisão da empilhadeira, assim como travamentos e desligamentos repentinos do sistema Lego Mindstorms EV3. A empilhadeira, também, só executa um comando por vez (não é possível, por exemplo, andar e mover o garfo ao mesmo tempo, ou andar e fazer uma curva simultaneamente). Com relação ao armazém, seria importante implantar um sistema de medidas em escala para facilitar a criação de modelos de simulação baseados em galpões reais e, também, um sistema de identificação do deslocamento mais curto de um ponto a outro.

\section{CONSIDERAÇÕES FINAIS}

Foi possível constatar que a realidade aumentada é um recurso de grande utilidade na educação. Especialmente, no desenvolvimento de treinamentos ou simulações direcionados à logística e transportes, pois torna possível reproduzir situações reais de maneira simplificada, com maior segurança e em espaços reduzidos.
Como a RA ainda é pouco disseminada no Brasil, seus custos ainda são relativamente altos, dificultando seu uso no ramo educacional. Nessa perspectiva, é pertinente que sejam desenvolvidas mais pesquisas que visem a explorar o potencial da realidade aumentada na educação, como por exemplo em aulas práticas em salas de aula, para que seu uso seja difundido e, assim, mais pessoas tenham acesso a este amplo recurso.

O modelo desenvolvido neste trabalho foi realizado como teste somente em laboratório, assim se faz necessária a utilização de mais testes, utilizando indivíduos que desejam aprender a prática de movimentação de materiais. Com isso, esse material será de grande utilidade em cursos livres de logística, aulas práticas de movimentação de materiais entre outros.

Desta forma, possibilita-se uma familiarização prática e simples do aluno com os comandos da empilhadeira e, assim, contribui-se para a redução de dificuldades e compreensão das aulas práticas, além de contribuir para melhora da motivação e, então, aprimorar o processo de ensino e aprendizagem desses alunos. Sendo assim, o material desenvolvido poderá ser utilizado para estudos preliminares na área educacional no campo da logística, que é o intuito do trabalho, podendo ser utilizado em treinamentos.

\section{REFERÊNCIAS}

AZUMA, R. A. Survey of Augmented Reality. Teleoperators and Virtual Environments, v. 6, n. 4, p. 355-385, 1997.

AZUMA, R. et al. Recent advances in augmented reality. IEEE computer graphics and applications, v. 21, n. 6, p. 34-47, 2001.

CAMPOS, A. M.; NUNES, G. B.; CHAGAS, N. N. Manual de Utilização: LALT Warehouse Realidade Aumentada. Campinas, 2018.

CARDOSO, A.; LAMOUNIER JR, E. A. Aplicações de RV e RA na Educação e Treinamento. In: COSTA, R. M.; RIBEIRO, M. W. S. (Orgs.). Aplicações de Realidade Virtual e Aumentada. Porto Alegre: 
Sociedade Brasileira de Computação, v. 1, p. 53-68, 2009.

CARVALHO, F. C. A.; IVANOFF, G. B. Tecnologias que educam: ensinar e aprender com as tecnologias de informação e comunicação. Pearson Prentice Hall, 2010

CASTRO, R., et al. A utilização de interação natural em ambientes tridimensionais para treinamento no setor elétrico. Anais... Workshops do Congresso Brasileiro de Informatica na Educação, 2014.

CHANG, G.; MORREALE, P.; MEDICHERLA, P. (2010). Applications of Augmented Reality Systems in Education. In: GIBSON, D.; DODGE, B. (Eds.). Proceedings... SITE 2010 - Society for Information Technology \& Teacher Education International Conference (pp. 1380-1385). San Diego, CA, USA: Association for the Advancement of Computing in Education (AACE).

DOT DIGITAL GROUP. Realidade Virtual e Realidade Aumentada. [S. 1.], 15 maio 2017. Disponível em: https://d335luupugsy2.cloudfront.net/cms/file s/32249/152450642720180420-DOTCMebook_RA_RV_2018.pdf. Acesso em: 25 mai. 2019.

HAMILTON, K. E. Augmented reality in education. Proceedings... SXSW Interactive, 2011, Disponível em: https://augmentedreality-in-education.wikispaces.com/ Acesso em: 25 mai. 2019.

KIRNER, C.; ZORZAL, E. R. Aplicações Educacionais em Ambientes Colaborativos com Realidade Aumentada. Anais... XVI SIMPÓSIO BRASILEIRO DE INFORMÁTICA NA EDUCAÇÃO, Juiz de Fora, p. 114-124, 2005.

KENSKI, V. M. Educação e tecnologias: o novo ritmo da informação. Papirus educação. Campinas: Papirus: 2012.

KLOPFER, E. Augmented learning: research and design of mobile educational games. Cambridge, MA: MIT Press, 2008.
KÜCKELHAUS, M. Eleven reasons to consider augmented reality in logistics. Logistics \& Transport Focus, v. 17, n. 4, p. 14-17, 2015.

LIAROKAPIS, F.; ANDERSON, E. F. Using Augmented Reality as a Medium to Assist Teaching in Higher Education. Eurographics 2010 - Education Papers, The Eurographics Association, p. 9-16, 2010.

MASE, K., KADOBAYASHI, R., NAKATSU, R. Meta-Museum: A supportive AugmentedReality Environment for Knowledge Sharing. In: Conference VSMM, 1996.

MATTAR, J. Games em educação: como os nativos digitais aprendem. São Paulo: Pearson Prentice Hall, 2010.

MENDONÇA, R. L.; MUSTARO, P. N. Como tornar aplicações de realidade virtual e aumentada, ambientes virtuais e sistemas de realidade mista mais imersivos. In: RIBEIRO, M. W. S.; ZORZAL, E. R. Realidade Virtual e Aumentada: Aplicações e Tendências. Uberlândia: Editora SBC, 2011.

MILGRAM, P. et al. Augmented Reality: A class displays on the reality-virtuality continuum. In: SPIE, Telemanipulator and Telepresence Technologies, vol. 2351, 1994.

O'MALLEY, C.; STANTON FRASER, D. Literature Review in Learning with Tangible Technologies, 2004.

PEDROSA, S. M. P. A.; ZAPPALAGUIMARÃES, M. A. Realidade virtual e realidade aumentada: refletindo sobre usos e benefícios na educação. Revista Educação e Cultura Contemporânea, v. 16, n. 43, p. 123146, 2019.

PRENSKY, M. Aprendizagem baseada em jogos digitais. São Paulo: Editora

Senac São Paulo, 2012.

SANTOS, G.; RESENDE, L. M. M. O Desafio Metodológico no uso de Novas Tecnologias: Um estudo em uma Instituição de Ensino da cidade de Itararé-SP. Revista Tecnologias na Educação, Ano 6, n. 10, jul. [n.p.], 2014. 
SILVEIRA, I. F.; ARAÚJO JR, C. F. Tecnologia da Informação e Educação: pesquisa e aplicações. São Paulo: Andross Editora, 2006.
TORI, R.; KINER, C. Livro do Pré-Simpósio. VII Symposium on Virtual Reality. São Paulo, 19 out., 2004.

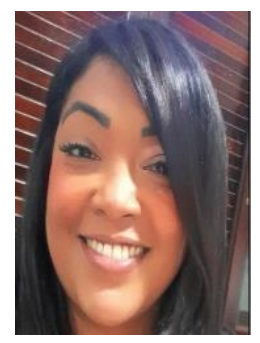

\section{DADOS BIOGRÁFICOS DOS AUTORES}

Juliana Ferreira de Vales possui graduação em Logística com ênfase em Transportes pela Faculdade de Tecnologia da Zona Leste FATEC (2007), é Licenciada em Pedagogia (2017), possui pós-graduação em Engenharia de Produção (2015). Atualmente é professora do Centro Estadual de Educação Tecnológica Paula Souza e Universidade Brasil, em disciplinas de Logística e Administração. Atualmente é coordenadora da Classe Descentralizada da ETEC da Zona Leste CEU Azul da Cor do Mar. Foi professora do SENAC de cursos livres, atuando no VIA RÁPIDA EMPREGOS e também durante cinco anos em Ensino Superior. Atuou durante sere anos em Industria Plástica na área de Logística e desde 2011 atua na área de Educação, é Mestranda em Engenharia Civil, área de atuação Transportes, pela UNICAMP.

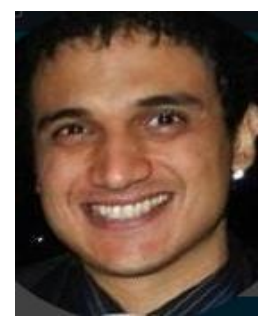

Allex Martins Campos é graduado em Física pela UNICAMP, possui curso de Comunicação Social com ênfase em Publicidade e Propaganda. Também possui formação em Engenharia de Automação e controle. Atualmente desenvolve atividade de manutenção de software para suporte acadêmico no LALT (Laboratório de Aprendizagem em Logística e Transportes).

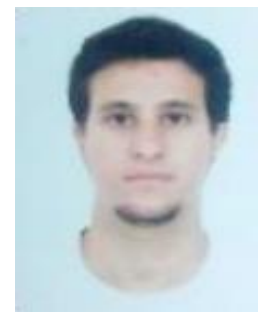

Gabriel Bulgarelli Nunes é graduando em Engenharia Civil pela UNICAMP, possui curso-tecnico-profissionalizante em Técnico em Mecatrônica pelo Colégio Técnico de Campinas (2011) e Ensino Médio pelo Colégio Técnico de Campinas (2011). Tem experiência na área de Engenharia Civil.

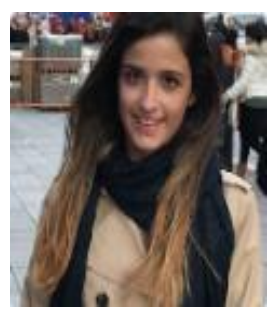

Nathalia Nobrega Chagas é graduanda em Engenharia Civil pela Unicamp. Participou do programa PIBIC/PIBITI com o projeto "Realidade aumentada como recursos na aprendizagem de logística e Transportes". Possui Ensino Médio pela Luella High School (2014). Tem experiência na área de Engenharia Civil. 


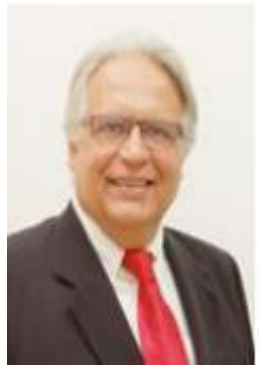

Orlando Fontes Lima Júnior é Professor Titular do Departamento de Geotecnia e Transportes da Faculdade de Engenharia Civil, Arquitetura e Urbanismo (FEC) da UNICAMP. Obteve a Livre Docência (2004) na UNICAMP, o Doutorado (1995) e Mestrado (1988) em Engenharia de Transportes pela Universidade de São Paulo. Na Graduação (1982) concluiu Engenharia Naval pela Universidade de São Paulo. Realizou Pós-Doutorado na Universidade Estadual de Campinas (2006) e na Bournemouth University (2007). Foi Professor da Escola Politécnica da Universidade de São Paulo (1990 a 1996). Foi Prefeito da Cidade Universitária "Zeferino Vaz" da Unicamp (1998 a 2002) e Coordenador de Extensão e Eventos da FEC/Unicamp (2010 a 2013), Vice Reitor Executivo de Administração da UNICAMP (2014) e atualmente é vice coordenador de Extensão e Eventos da FEC/UNICAMP e coordena o Laboratório de Aprendizagem em Logística e Transportes (LALT). Na Associação Nacional de Pesquisa e Ensino e Transportes (ANPET) foi Diretor e Presidente. Publicou diversos artigos em periódicos especializados e trabalhos em anais de eventos. É membro de bancas examinadoras de Mestrado e Doutorado. Na graduação atua em dois cursos da UNICAMP, Engenharia Civil e Arquitetura e Urbanismo. Na Pós-Graduação atua em dois Programas de Pós-Graduação da UNICAMP, Engenharia Civil e Arquitetura, Tecnologia e Cidade, orientando pesquisas de mestrado e de doutorado. Possui experiência na área de Engenharia de Transportes, com ênfase em Operações de Transportes. Atua principalmente nos seguintes temas: Transporte, Logística, Desempenho. 